\title{
Cultural and economic determinants of geographical mortality patterns in The Netherlands
}

\author{
Johan P Mackenbach, Anton E Kunst, Caspar W N Looman
}

\begin{abstract}
Study objective-The geographical pattern of mortality in The Netherlands is dominated by an area of relatively high mortality in the southern part of the country. The aim was to analyse the background of this geographical mortality pattern in the early 1980 s, and its evolution over time since the early 1950 s.
\end{abstract}

Design-Mortality data by district $(n=39)$, cause of death (13 large causes, "symptoms and ill defined conditions", all other causes), and time period (1950-54, $1960-64,1970-74,1980-84$ ) were available from the Netherlands Central Bureau of Statistics. Standardised mortality ratios were calculated, and the logarithms of these were related to three sociodemographic characteristics using multiple, ordinary least squares regression analysis.

Setting-This study used data for the whole Dutch population.

Main results-Although the geographical mortality pattern has been rather stable over the last decades, a clear tendency towards convergence is also apparent. Approximately $90 \%$ of the current excess mortality in the southern part of the country is due to cardiovascular diseases. The results of regression analysis show that the excess mortality is primarily related to the high percentage of Roman Catholics in this part of the country, and additionally to a slightly lower average income. In The Netherlands, a higher percentage of Roman Catholics in the population is linked with higher all cause mortality rates, as well as with higher mortality rates for lung cancer, ischaemic heart disease, cerebrovascular disease, arterial disease, and chronic nonspecific lung disease. Survey data show that these associations are partly due to a higher prevalence of smoking among Roman Catholics. As in many other countries, a lower average income is linked with high all cause mortality rates in The Netherlands. Cause specific data show negative associations for stomach cancer, ischaemic heart disease, cerebrovascular disease, chronic non-specific lung disease, and traffic accidents. Since the early 1950 s the association between geographical mortality patterns and the percentage of Roman Catholics in the population has gradually become less strongly positive. This suggests that the convergence of the mortality rates in the South towards the national average may be related to a gradual lessening of differences in lifestyle between population groups.

Conclusions-Both cultural and economic factors are important in the explanation of geographical mortality patterns in The Netherlands.

The Netherlands have low mortality rates by international standards: in the early 1980s the average life expectancy at birth was 75.1 years, which gave the Netherlands the fifth position on the international league table after Japan, Iceland, Sweden, and Norway. ${ }^{1}$ Despite the low overall rates and the small size of the country, geographical variation in mortality within the Netherlands is not negligible (fig 1): at district level standardised mortality ratios for all cause mortality ranged from 0.85 to 1.09 in $1980-84$. These districts are usually grouped into five large regions: North, East, West, Southwest and South. The geographical pattern of mortality in The Netherlands is dominated by a contiguous area of relatively high mortality almost coinciding with the South region. The Southwest and North regions have generally low mortality rates, whereas the West and East regions are more heterogeneous.

As table I shows, the situation observed in 1980-1984 has existed for many years. The general features of the current situation could already be distinguished in 1950-1954: high mortality in the South region, and low mortality in the Southwest and North regions. There is, however, a clear tendency of convergence towards the national average both in the South region (which slowly but not unimportantly improved its position) and in the North region (which lost part of its advantage).

A comprehensive study of this mortality pattern has not yet been made, despite the fact that the higher mortality levels in the South region have been known for a long time. Age standardised death rates were already higher in an analysis covering the years 1926-1935. ${ }^{2}$ The unfavourable mortality position of this region probably originated in the late nineteenth century: the dramatic mortality decline which marked the beginning of the transition to the modern mortality regime started earlier in other parts of the country. ${ }^{3}$ Some have argued that this differential development was primarily related to cultural factors, ie, that modern concepts of hygiene, birth control etc, have penetrated less quickly in the South region than elsewhere. ${ }^{3}$ Others have defended the view that more rapid economic development of other parts of the country, especially of the West region, has caused the difference in mortality decline. ${ }^{4}$ 


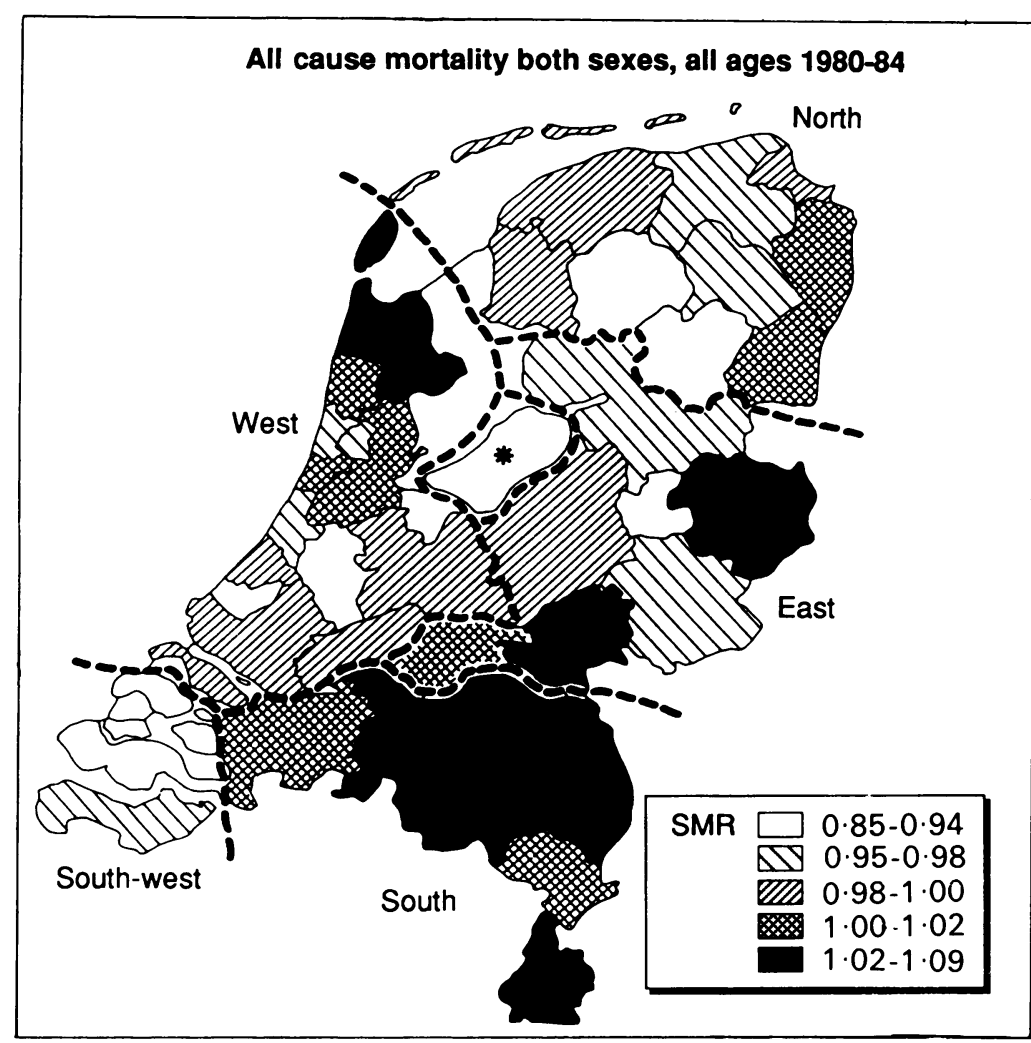

Figure 1 Geographical variation in all cause mortality in The Netherlands, 1980-84. The 39 districts have been grouped in five large regions: North, East, West, Southwest and South. District marked with an asterisk $\left(^{\star}\right)$, Zuidelijke Ifsselmeerpolders, occupies a separate position.

The latter viewpoint, emphasising the importance of economic factors in the explanation of regional variation in mortality, is represented rather widely in international reports. Close links between economic factors and mortality at the regional levels have been observed in many countries. England and Wales provide the classical example, with high mortality in the North and Northwest regions, characterised by unfavourable economic circumstances, and low mortality in the Southeast and Southwest regions and East Anglia. ${ }^{5}$ It was shown recently that much of the difference in mortality between Scotland and England and Wales is related to differences in the prevalence of material deprivation. ${ }^{6}$ In Finland, Sweden, and Norway, ${ }^{7}$ as well as in France, ${ }^{8}$ and the United States, ${ }^{9} 10$ similar relationships have been noted.

Table I Evolution of the distribution of all cause mortality by region and district in The Netherlands, 1950-84

\begin{tabular}{|c|c|c|c|c|}
\hline \multirow{2}{*}{$\begin{array}{l}\text { Region } \\
\text { (number of } \\
\text { districts) }\end{array}$} & \multicolumn{4}{|c|}{$\begin{array}{l}\text { Standardised mortality ratios } \\
\text { (range of variation by districts) }\end{array}$} \\
\hline & $1950-54$ & $1960-64$ & $1970-74$ & $1980-84$ \\
\hline $\begin{array}{l}\text { North } \\
(9) \\
\text { East } \\
(7) \\
\text { West } \\
(14) \\
\text { Southwest } \\
(2) \\
\text { South } \\
(7) \\
\text { Z IJ Pb } \\
\text { All } \\
(40)\end{array}$ & $\begin{array}{l}0.936 \\
(0.90-0.97) \\
1.003 \\
(0.95-1 \cdot 04) \\
0.989 \\
(0.93-1 \cdot 04) \\
0.990^{\mathrm{a}} \\
(0.93-1.02) \\
1.092 \\
(1.06-1 \cdot 15) \\
1.000 \\
(0.90-1 \cdot 15)\end{array}$ & $\begin{array}{l}0.938 \\
(0 \cdot 91-0 \cdot 97) \\
1 \cdot 010 \\
(0 \cdot 95-1 \cdot 06) \\
0.990 \\
(0 \cdot 94-1 \cdot 04) \\
0.919 \\
(0 \cdot 90-0 \cdot 96) \\
1 \cdot 084 \\
(1 \cdot 05-1 \cdot 14) \\
0 \cdot 79 \\
1 \cdot 000 \\
(0 \cdot 79-1 \cdot 14)\end{array}$ & $\begin{array}{l}0.960 \\
(0.91-0.99) \\
1 \cdot 016 \\
(0.97-1 \cdot 04) \\
0.988 \\
(0.90-1 \cdot 03) \\
0.902 \\
(0 \cdot 88-0.94) \\
1 \cdot 057 \\
(1 \cdot 01-1 \cdot 11) \\
0 \cdot 77 \\
1 \cdot 000 \\
(0 \cdot 77-1 \cdot 11)\end{array}$ & $\begin{array}{l}0.975 \\
(0.92-1.01) \\
1.007 \\
(0.94-1.06) \\
0.991 \\
(0.92-1.03) \\
0.924 \\
(0.90-0.96) \\
1.046 \\
(1.02-1.09) \\
0.85 \\
1.000 \\
(0.85-1.09)\end{array}$ \\
\hline
\end{tabular}

A causal interpretation of these relationships is supported by the fact that the risk of dying is strongly linked to socioeconomic conditions at the individual level too. Again, mortality data from England and Wales illustrate this quite clearly. The Decennial supplement on occupational mortality for 1979-83 showed that the death rate for men aged 15-64 in occupational class $\mathrm{V}$ (unskilled workers) was as much as 2.5 times the rate for men in class I (professionals). ${ }^{11}$ The OPCS Longitudinal Study showed that the death rate for men aged 15-64 in class V, followed up since the 1971 Census, was 1.9 times the rate for men in class I in 1976-81. ${ }^{12}$ Although information from other countries is more scanty, publications from Finland, ${ }^{13}$ Sweden, ${ }^{14}$ Norway, ${ }^{15}$ Denmark, ${ }^{16}$ France, ${ }^{17}$ the United States, ${ }^{18}$ and New Zealand ${ }^{19}$ suggest that socioeconomic inequality in the face of death is a generalised phenomenon in western societies.

On the other hand, the "cultural" viewpoint cited above has a strong intuitive appeal for those familiar with the Dutch situation, because the South region has certain distinctive cultural characteristics. Compared to economic factors, cultural factors have attracted much less attention in international reports on regional mortality differences, despite the fact that many causes of death are behaviourally mediated, and that there must be cultural differences between regions in many countries. An important exception is Belgium, where the "language frontier" between the Flemish and French speaking part of the country has been shown to separate two mortality regions, with considerably higher mortality rates in French speaking areas. ${ }^{2021}$ This cannot be explained by economic factors. ${ }^{22}$

The analysis reported here aimed at finding clues to the explanation of the geographical pattern of mortality in The Netherlands, with a focus on the higher mortality rates in the South region and their evolution over time. It consists of three parts: (1) an analysis of the contributions of specific causes of death to the observed all cause mortality pattern in 1980-84; (2) a multiple regression analysis relating all cause and cause specific mortality in 1980-84 to a number of sociodemographic characteristics; (3) an analysis of changes over time since 1950-54, both with regard to the nature of the associations between mortality and sociodemographic characteristics and with regard to changes in the geographical distribution of these characteristics.

\section{Methods}

Numbers of deaths by age $(<1,1-4,5-14, \ldots$. 85-94, 95 + years), sex, calendar year (1950-84), district, and four digit number of the International classification of diseases (ICD) were available from a large computer file supplied by the Netherlands Central Bureau of Statistics. Mid-year population numbers by age, sex, calendar year, and region were available from several sources based upon the Dutch population register which is kept up to date continuously.

For statistical purposes, The Netherlands have been divided into 40 so called COROP districts with an average population size of around 360000 , each representing a geographical area 
serviced by one or more larger cities. District No 40 (Zuidelijke IJsselmeer Polders), land which was recently claimed from the waters of the former Zuiderzee, was omitted from all the following analyses because its population was very small before the end of the study period and information on determinants of mortality was mostly lacking. For presentation purposes we shall frequently summarise descriptive data by grouping the 39 remaining districts into the five large regions mentioned in the introduction.

The causes of death included in the analysis were the largest causes of death in 1980-84: five cancers (stomach, colon, lung, breast, prostate), four cardiovascular diseases (ischaemic heart disease, other heart disease, cerebrovascular disease, arterial disease), two respiratory diseases (influenza/pneumonia, chronic non-specific lung disease), and two external causes (traffic accidents, other accidents), as well as a category "symptoms and ill defined conditions", and all other causes. The 13 specific causes accounted for around $65 \%$ of total mortality in $1980-84$.

Regional mortality rates were standardised for differences in the age and sex structure of populations by calculating standardised mortality ratios. National mortality rates by age and sex for each time period were used as standard rates. For the analysis of the contribution of separate causes of death to lower or higher overall mortality, indirectly standardised death rates were calculated by multiplying the standardised mortality ratios by the national death rates.

The variables used for the exploration of possible determinants of regional mortality patterns were average income per head of population, percentage of population living in larger cities, and percentage of population of Roman Catholic denomination. The selection of these variables was guided by an analysis of a set of 15 sociodemographic variables for a recent time period (1980-84). This set of variables included a wide range of indicators of both economic and cultural differences with potential relevance for the explanation of mortality patterns. We decided to ignore other than sociodemographic variables, such as climatic factors (differences are very small in The Netherlands), health care factors (supply of health care was shown to be not related to regional mortality levels ${ }^{23}$ ), and specific occupational exposures (percentage population employed in a specific occupation is too small for any mortality effects to be detected). A principal components analysis (without rotation) showed that the first three factors, which accounted for $68 \%$ of the variation, each represented a clearly interpretable dimension: a socioeconomic dimension (related to income, education, white $v$ blue collar workers), an urbanisation dimension (related to no religious affiliation, left wing voters, single persons, few elderly people, one parent families, divorce rate, larger cities), and a religious dimension (related to Roman Catholicism, few right wing voters). The variables with the highest loading on each of these factors were average income, percentage population in larger cities, and percentage population of Roman Catholic denomination, respectively. The latter were therefore also collected for earlier time periods, for which data collection would otherwise have been very time consuming, and used in the regression analyses.

Table II gives some summary data on the geographical distribution of these sociodemographic variables in The Netherlands during the last decades. The definition of these variables is given in the notes of this table. In the West region, where the three largest cities of Amsterdam, The Hague, and Rotterdam are located, the percentage population in larger cities was the highest in the country. This region is generally regarded as the economic and cultural centre of the country, which is also reflected in a high average income. At the other extreme, the North and Southwest regions are still rather rural in character. The North region is further characterised by the fact that the large majority of its population has its cultural roots in the Protestant religious tradition (so that the percentage Roman Catholic is very low), and by a rather low average income. On an urban-rural axis, the East and South regions occupied an intermediary position. The population of the South region is mainly Roman Catholic.

It is important to note that, although the three sociodemographic variables were rather skewedly distributed across the large regions, the distribution is diffuse enough to permit meaningful analyses. For example, the percentage Roman Catholic was uniformly high in the South, but isolated districts with higher than average percentages could also be found in the East, West, and Southwest regions.

During the period 1950-84, changes in the geographical distribution of these characteristics were small: correlations between district values
Table II The distribution of average income, percentage in larger cities, and percentage Roman Catholic by region and district in The Netherlands, 1950-54 and 1980-84

\begin{tabular}{|c|c|c|c|c|c|c|}
\hline \multirow{3}{*}{$\begin{array}{l}\text { Region } \\
\text { (number of } \\
\text { districts }\end{array}$} & \multicolumn{6}{|c|}{ Regional values (range of variation by district) } \\
\hline & \multicolumn{2}{|c|}{ Average income ${ }^{\mathrm{a}}$} & \multicolumn{2}{|c|}{ Percentage in larger cities ${ }^{b}$} & \multicolumn{2}{|c|}{ Percentage Roman Catholic ${ }^{\mathrm{c}}$} \\
\hline & $1950-54$ & $1980-84$ & $1950-54$ & $1980-84$ & $1950-54$ & $1980-84$ \\
\hline $\begin{array}{l}\text { North } \\
\text { (9) } \\
\text { East } \\
(7) \\
\text { West } \\
(14) \\
\text { Southwest } \\
\text { (2) } \\
\text { South } \\
\text { (7) } \\
\text { All } \\
\text { (39) } \\
\end{array}$ & $\begin{array}{l}4 \cdot 2 \\
(3 \cdot 3-4 \cdot 7) \\
4 \cdot 2 \\
(3 \cdot 7-4 \cdot 6) \\
5 \cdot 2 \\
(4 \cdot 2-6 \cdot 2) \\
4 \cdot 7 \\
(4 \cdot 5-5 \cdot 0) \\
4 \cdot 0 \\
(3 \cdot 4-4 \cdot 4) \\
4 \cdot 7 \\
(3 \cdot 3-6 \cdot 2) \\
\end{array}$ & $\begin{array}{c}7 \cdot 9 \\
(7 \cdot 1-8 \cdot 8) \\
8 \cdot 4 \\
(7 \cdot 8-9 \cdot 0) \\
10 \cdot 0 \\
(9 \cdot 0-11 \cdot 0) \\
9 \cdot 1 \\
(9 \cdot 1-9 \cdot 1) \\
8 \cdot 7 \\
(8 \cdot 0-9 \cdot 4) \\
9 \cdot 2 \\
(7 \cdot 1-11 \cdot 0) \\
\end{array}$ & $\begin{array}{l}16 \cdot 9 \\
(0 \cdot 0-47 \cdot 2) \\
20 \cdot 8 \\
(0 \cdot 0-52 \cdot 0) \\
55 \cdot 0 \\
(0 \cdot 0-85 \cdot 8) \\
0 \cdot 0 \\
(0 \cdot 0-0 \cdot 0) \\
20 \cdot 5 \\
(0 \cdot 0-45 \cdot 1) \\
36 \cdot 2 \\
(0 \cdot 0-85 \cdot 8) \\
\end{array}$ & $\begin{array}{l}16 \cdot 0 \\
(1 \cdot 3-46 \cdot 3) \\
27 \cdot 3 \\
(0 \cdot 0-44 \cdot 7) \\
47 \cdot 6 \\
(10 \cdot 2-91 \cdot 3) \\
0 \cdot 0 \\
(0 \cdot 0-0 \cdot 0) \\
23 \cdot 7 \\
(0 \cdot 0-36 \cdot 9) \\
33 \cdot 7 \\
(0 \cdot 0-91 \cdot 3) \\
\end{array}$ & $\begin{array}{l}6 \cdot 8 \\
(1 \cdot 3-16 \cdot 5) \\
35 \cdot 0 \\
(10 \cdot 7-63 \cdot 0) \\
27 \cdot 2 \\
(7 \cdot 7-47 \cdot 1) \\
25 \cdot 5 \\
(13 \cdot 9-49 \cdot 4) \\
91 \cdot 3 \\
(83 \cdot 6-98 \cdot 1) \\
38 \cdot 9 \\
(1 \cdot 3-98 \cdot 1)\end{array}$ & $\begin{array}{l}8 \cdot 1 \\
(3 \cdot 5-20 \cdot 1) \\
35 \cdot 8 \\
(13 \cdot 4-62 \cdot 0) \\
28 \cdot 2 \\
(11 \cdot 8-46 \cdot 1) \\
26 \cdot 0 \\
(13 \cdot 1-55 \cdot 2) \\
88 \cdot 3 \\
(81 \cdot 1-95 \cdot 3) \\
40 \cdot 8 \\
(3 \cdot 5-95 \cdot 3)\end{array}$ \\
\hline
\end{tabular}


for $1950-54$ and $1980-84$ were $0 \cdot 61,0 \cdot 77$, and $1 \cdot 00$ for average income, percentage in larger cities, and percentage Roman Catholic, respectively. The most important change occurred for average income: the unfavourable situation of districts in the South region generally improved over time (from $15 \%$ to $5 \%$ below the national average), whereas those of districts in the North region deteriorated (from $11 \%$ to $14 \%$ below the national average).

The logarithms of the district standardised mortality ratios were related to the sociodemographic variables through multiple, ordinary least squares regression analysis. Residual analyses have been carried out which showed that the linearity assumption was reasonable in practically all cases.

\section{Results}

The higher mortality rates in the South region as observed in 1980-1984 are almost completely due

Table III The contribution of specific causes of death to higher or lower overall mortality in five large regions, The Netherlands 1980-84

\begin{tabular}{|c|c|c|c|c|c|}
\hline & \multicolumn{5}{|c|}{$\begin{array}{l}\text { Excess mortality (deaths per } 10000 \text { person years, age } \\
\text { standardised) })^{\mathrm{a}}\end{array}$} \\
\hline & North & East & West & Southwest & South \\
\hline $\begin{array}{l}\text { Cancer of stomach } \\
\text { Cancer of colon } \\
\text { Cancer of lung } \\
\text { Cancer of breast }{ }^{b} \\
\text { Cancer of prostate }\end{array}$ & $\begin{array}{r}31 \\
-0 \\
-102 \\
-10 \\
3\end{array}$ & $\begin{array}{r}-14 \\
4 \\
-24 \\
-0 \\
-2\end{array}$ & $\begin{array}{r}-12 \\
-3 \\
29 \\
6 \\
7\end{array}$ & $\begin{array}{r}63 \\
-4 \\
-118 \\
-12 \\
-13\end{array}$ & $\begin{array}{r}17 \\
6 \\
33 \\
-7 \\
-15\end{array}$ \\
\hline $\begin{array}{l}\text { Ischaemic heart disease } \\
\text { Other heart disease } \\
\text { Cerebrovascular disease } \\
\text { Arterial disease }\end{array}$ & $\begin{array}{r}152 \\
-47 \\
-29 \\
-35\end{array}$ & $\begin{array}{r}1 \\
57 \\
33 \\
4\end{array}$ & $\begin{array}{r}-98 \\
-8 \\
-32 \\
-2\end{array}$ & $\begin{array}{r}-68 \\
-62 \\
-142 \\
-22\end{array}$ & $\begin{array}{r}172 \\
11 \\
113 \\
29\end{array}$ \\
\hline $\begin{array}{l}\text { Influenza/pneumonia } \\
\text { CNSLD }^{\mathrm{c}}\end{array}$ & $\begin{array}{l}-16 \\
-50\end{array}$ & $\begin{array}{r}0 \\
41\end{array}$ & $\begin{array}{r}5 \\
-6\end{array}$ & $\begin{array}{l}-51 \\
-88\end{array}$ & $\begin{array}{r}6 \\
19\end{array}$ \\
\hline $\begin{array}{l}\text { Traffic accidents } \\
\text { Other accidents }\end{array}$ & $\begin{array}{r}24 \\
-5\end{array}$ & $\begin{array}{r}16 \\
-4\end{array}$ & $\begin{array}{r}-22 \\
4\end{array}$ & $\begin{array}{l}-6 \\
-8\end{array}$ & $\begin{array}{r}22 \\
-5\end{array}$ \\
\hline $\begin{array}{l}\text { Symptoms and ill defined } \\
\text { conditions } \\
\text { All other causes }\end{array}$ & $\begin{array}{l}-79 \\
-40\end{array}$ & $\begin{array}{r}-57 \\
5\end{array}$ & $\begin{array}{l}37 \\
18\end{array}$ & $\begin{array}{r}80 \\
-170\end{array}$ & $\begin{array}{r}-4 \\
-21\end{array}$ \\
\hline All causes & -203 & 60 & -77 & -621 & 376 \\
\hline
\end{tabular}

${ }^{a}$ Difference between regional age standardised death rate and national death rate

b In order to permit calculation of contribution to total mortality (both sexes), rates have been In order to permit calculation of contribution
calculated for the total population (both sexes)

Chronic non-specific lung disease

Table IV Association between district mortality and three sociodemographic characteristics, by cause of death, The Netherlands 1980-84

\begin{tabular}{lcccc}
\hline & \multicolumn{2}{l}{$\begin{array}{l}\text { Multiple regression coefficient } \\
\text { if } p<0.05)\end{array}$} & \\
\cline { 2 - 4 } & $\begin{array}{l}\text { Average } \\
\text { income }\end{array}$ & $\begin{array}{l}\text { Percentage } \\
\text { in larger } \\
\text { cities }\end{array}$ & $\begin{array}{l}\text { Percentage } \\
\text { Roman } \\
\text { Catholic }\end{array}$ & $\begin{array}{l}\text { Percentage } \\
\text { variance } \\
\text { explained }\end{array}$ \\
\hline Stomach cancer & -0.0471 & -0.00239 & - & 39 \\
Colon cancer & - & - & - & 9 \\
Lung cancer & +0.0314 & +0.00222 & +0.00274 & 64 \\
Breast cancer & - & - & - & 14 \\
Prostate cancer & -0.0442 & - & -0.00189 & 38 \\
Ischaemic heart disease & - & - & +0.00111 & 56 \\
Other heart disease & - & -0.00208 & +0.00196 & 35 \\
Cerebrovascular disease & - & +0.00272 & +0.00213 & 25 \\
Arterial disease & - & +0.00346 & +0.00265 & 40 \\
Influenza/pneumonia & -0.1050 & -0.00286 & - & 62 \\
CNSLD & - & +0.00158 & - & 12 \\
Traffic accidents & - & - & +0.00333 & 30 \\
Other accidents & - & +0.00101 & - & 23 \\
Ill defined conditions & -0.0149 & +0.00062 & +0.00098 & 58 \\
All other & & & &
\end{tabular}

${ }^{a}$ Multiple regression analysis $(n=39)$

b Curnic non-specific lung disease to higher cardiovascular mortality (table III). Although mortality rates for many other causes of death are also raised, the excess mortality for the four cardiovascular conditions included in the analysis accounts for $86 \%$ of the excess all cause mortality.

In contrast to this, the lower mortality in the Southwest region, which has the most favourable rates in the country, is a more generalised phenomenon. Important contributions come from cancer (especially lung cancer), cardiovascular diseases, respiratory diseases, and all other causes. One important difference between the Southwest and the North regions is that the latter has high ischaemic heart disease mortality rates, leading to a much smaller deficit in all cause mortality, despite low mortality from cancer (especially lung cancer) and respiratory diseases.

The three selected sociodemographic characteristics appear to "explain" $58 \%$ of the variance in all cause mortality at district level (table IV). Percentage Roman Catholic makes the largest contribution: both the zero order and the partial (controlling for the other two variables) correlations between mortality and percentage Roman Catholic are higher $(0.61$ and 0.63$)$ than those between mortality and either average income $(-0.30$ and -0.47$)$ or percentage in larger cities $(0.15$ and 0.33$)$.

Mortality is generally higher in districts with a high percentage of Roman Catholics in the population. This applies to all cause mortality as well as to mortality from lung cancer, ischaemic heart disease, cerebrovascular disease, arterial disease, influenza/pneumonia, and chronic nonspecific lung disease. The only negative association is found for prostate cancer. The positive association between total mortality and percentage Roman Catholic is not only found in an analysis covering all 39 districts, but also in an analysis excluding the seven districts in the South region, where the percentage Roman Catholic is extremely and uniformly high. The value of the regression coefficient is practically the same in both analyses $(0.00098$ with 39 districts, 0.00099 with 32 districts). This suggests that the association is not biased by the presence of third factors specific to the South region. Figure 2 gives a visual impression of the relationship between percentage Roman Catholic and total mortality.

The association between average income and all cause mortality is negative. The strongest association is found for traffic accidents. Lung cancer is the only specific cause of death with has higher death rates in more prosperous areas.

The degree of urbanisation is positively associated with mortality. Lung cancer, arterial disease, respiratory diseases, and other accidents are more frequent as a cause of death in urbanised districts.

A combination of these results with the data on the geographical distribution of the three sociodemographic variables (table II) suggests that the high mortality rates in the South region are primarily related to the high percentage of Roman Catholics in the population, or to characteristics which are closely associated with this. An analysis of regression residuals confirms this. Controlling only for percentage Roman 


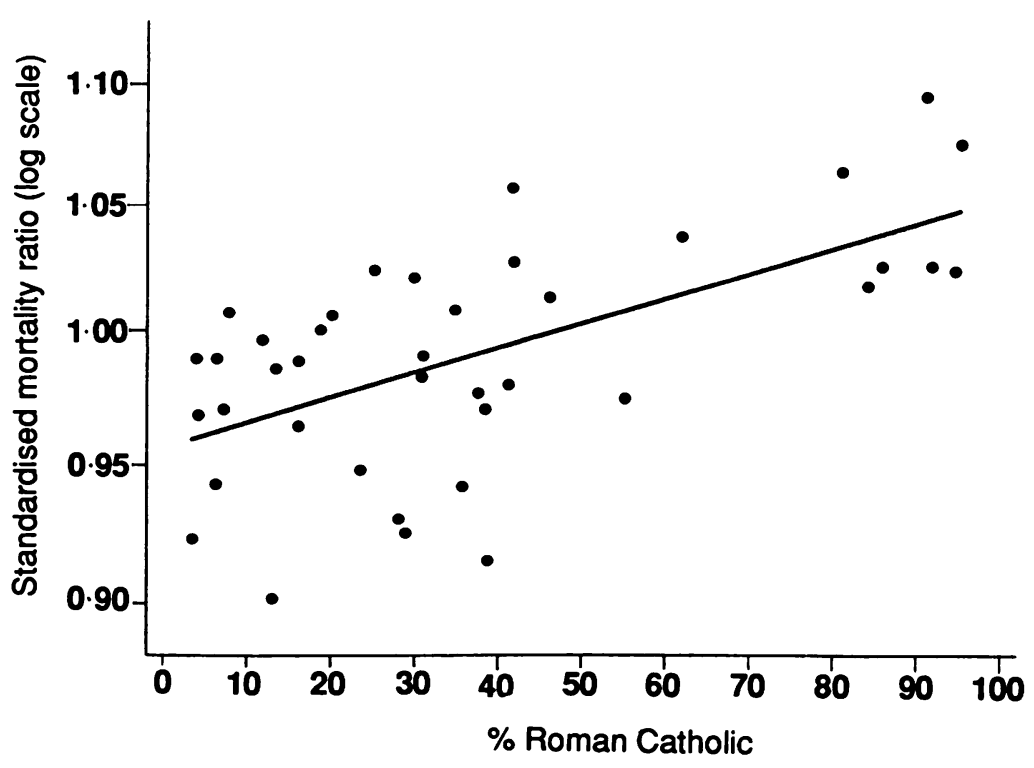

Figure 2 Plot of standardised mortality ratio (SMR) (total mortality) against percentage Roman Catholic, 39 districts, The Netherlands, 1980-84. The line represents the estimated regression line for log SMR on percentage Roman Catholic.

Catholic reduces the all cause mortality rates in most districts in the South region to values close to the national average. The slightly lower average income in this region makes an additional, but much smaller contribution.

As a check on, and further background to, the findings reported so far, we also studied the stability or evolution of the relationships between the three sociodemographic variables and mortality over a longer time period, 1950-84. There were notable changes in these relationships (table V).

The relationship between all cause mortality and average income became rather more negative over this period. In the early 1950 s the association was only slightly negative, and not statistically significant. In the early 1960 s the association appeared to have become slightly positive, but from then on it became ever more negative. The increasing importance of average income as a predictor of regional mortality levels is also apparent from the partial correlations with all cause mortality, which changed from -0.02 in $1950-54$ to -0.47 in $1980-84$. The two specific causes of death which were the most important contributors to this development were ischaemic heart disease and cerebrovascular disease. For both, the association with income was still positive in 1950-54. Between then and 1980-84 a dramatic reversal occurred.

The changes in the association between mortality and the other two sociodemographic variables are also noteworthy. Gradually, a relationship with degree of urbanisation emerged

Table $V$ Evolution of the association of all cause mortality with the three sociodemographic variables at district level in The Netherlands, 1950-84

\begin{tabular}{lllll}
\hline & \multicolumn{2}{l}{ Multiple regression coefficient } & \\
\cline { 2 - 4 } & $\begin{array}{l}\text { Average } \\
\text { income }\end{array}$ & $\begin{array}{l}\text { Percentage } \\
\text { in larger } \\
\text { cities }\end{array}$ & $\begin{array}{l}\text { Percentage } \\
\text { Roman } \\
\text { Catholic }\end{array}$ & $\begin{array}{l}\text { Percentage } \\
\text { variance } \\
\text { explained }\end{array}$ \\
\hline $1950-54$ & -0.0073 & -0.00011 & $0.00151^{\star}$ & 64 \\
$1960-64$ & 0.0057 & 0.00023 & $0.00151^{\star}$ & 70 \\
$1970-74$ & -0.0110 & 0.00048 & $0.00107^{\star}$ & 48 \\
$1980-84$ & $-0.0149 \star$ & $0.00062^{\star}$ & $0.00098^{\star}$ & 58 \\
\hline${ }_{0}<0.05$ & & & &
\end{tabular}

during these years. The association with percentage Roman Catholic, on the other hand, became less strong over time. Although this variable was the most important determinant of variation in mortality over the whole time period, it has steadily been losing ground. In 1950-54, the partial correlation between percentage Roman Catholic and all cause mortality was 0.80 , in $1980-84,0.63$.

These findings suggest that the convergence towards the national average of the higher mortality rates in the South region is due to a decrease of the excess mortality among Roman Catholics. The effect of the increase in relative income in this region (table II) was largely compensated for by a strengthening of the negative association between average income and mortality over the same period. By contrast, the convergence towards the national average of the lower mortality rates in the North region is not only related to a change in the relationship between mortality and religious variables, but also to a combination of declining relative income (table II) and a strengthening of the negative association of the latter variable with mortality.

\section{Discussion}

The relatively high mortality rates in the southern part of The Netherlands, which dominate the geographical mortality pattern of the country as a whole, appear to be largely due to cardiovascular diseases. Four cardiovascular diseases, which together account for only $43 \%$ of all deaths, account for $86 \%$ of the excess all cause mortality in the South in 1980-1984. This is remarkable because the South region already had relatively high mortality rates before cardiovascular diseases became the leading causes of death. At the turn of the century infectious diseases and (other) causes of infant mortality must have been the major contributors. This suggests that some very general factors, operating over a considerable time span and through seemingly unrelated disease categories, must underlie the excess mortality in the South region.

The main finding of the regression analyses is that of three sociodemographic variables which together explain $58 \%$ of the variance in all cause mortality at district level in The Netherlands in $1980-84$, the most clearly "cultural" of the three appeared to be the most important. In districts with a high percentage of Roman Catholics in the population all cause mortality as well as mortality from many specific causes of death is higher than the national average.

Before it was used in the regression analyses, the variable "percentage Roman Catholic" was selected from among a number of variables, which it was intended to represent. These other variables were also religion related (right wing voters mainly being orthodox Protestants). When the regression analyses are repeated with percentage Protestant instead of percentage Roman Catholic, positive associations are replaced by negative associations, with largely the same levels of significance and percentages of variance explained.

This suggests that it might indeed be religious affiliation, or characteristics influencing this/ 
influenced by this, that "explains" a part of the geographical pattern of mortality in The Netherlands. Unfortunately, no studies of the relationship between Roman Catholic versus Protestant religious affiliation and mortality at the individual level have been performed in The Netherlands. On the other hand, there are enough parallels to be found in other Western societies for us to be confident that religious affiliation may be an important determinant of individual mortality risks in The Netherlands too. ${ }^{24}$ There is the obvious parallel with studies of mortality in orthodox groups like the Mormons, ${ }^{25}$ Amish, ${ }^{26}$ or Seventh Day Adventists ${ }^{27}$ in the United States, which have very low mortality rates compared to the rest of the population. Mortality studies from the United States comparing (mainstream) Protestants and Roman Catholics also suggest differences but not necessarily in the same direction as in The Netherlands. ${ }^{28} 29$ In the United States, these differences are probably confounded by socioeconomic and ethnic differences. $^{24}$

No European studies on differences in mortality between Protestants and Roman Catholics are known to the authors. Religious affiliation is also not a common concern in studies on geographical variation in mortality, if only because in countries like England and Wales, France, and the Scandinavian countries the large majority of the population belongs to one Christian denomination. In countries like Switzerland and the Federal Republic of Germany, where, like in The Netherlands, the Reformation has left a divided church, with a certain degree of geographical segregation of Protestants and Roman Catholics, no studies like the one reported here have been performed.

The obvious hypothesis emerging from the association between mortality and religious affiliation is that "life style" factors are involved. One is inevitably reminded of Weber's classical analysis of the Protestant way of life, supposed to be characterised by rationality and self discipline. ${ }^{30}$ As a matter of fact, the positive associations of percentage Roman Catholic with mortality from lung cancer, cardiovascular diseases, and chronic non-specific lung disease (table IV) strongly suggest smoking behaviour as an intermediary factor. Survey data from The Netherlands show that Roman Catholic affiliation has consistently been associated with relatively high prevalence rates of cigarette smoking throughout the postwar period. ${ }^{31} 32$ One of the larger of these surveys, involving more than 30000 respondents, was held in $1972 .{ }^{33}$ The large number of respondents permits an analysis at district level, which shows that percentage Roman

Table VI The effect of adding the prevalence of smoking to a regression model already containing the three sociodemographic variables. Total mortality, The Netherlands, 1980-84

\begin{tabular}{|c|c|c|c|c|c|}
\hline & \multicolumn{5}{|c|}{ Multiple regression coefficient } \\
\hline & $\begin{array}{l}\text { Average } \\
\text { income }\end{array}$ & $\begin{array}{l}\text { Percentage } \\
\text { in larger } \\
\text { cities }\end{array}$ & $\begin{array}{l}\text { Percentage } \\
\text { Roman } \\
\text { Catholic }\end{array}$ & $\begin{array}{l}\text { Percentage } \\
\text { smoking } \\
\text { cigarettes }\end{array}$ & $\begin{array}{l}\text { Percentage } \\
\text { variance } \\
\text { explained }\end{array}$ \\
\hline $\begin{array}{l}\text { All causes, } \\
1980-84\end{array}$ & $-0.0144^{\star}$ & $0.00065^{\star}$ & $0.00069^{\star}$ & $0.0033^{\star}$ & 65 \\
\hline
\end{tabular}

Catholic is positively associated with the prevalence of smoking. When the prevalence of smoking is included in a regression model already containing the three sociodemographic variables, the size of the regression coefficient for the association between percentage Roman Catholic and total mortality becomes considerably (30\%) smaller, suggesting that part of the association can be explained by the higher prevalence of smoking among Roman Catholics (table VI). The higher mortality rates in the South region before the advent of smoking related diseases may have the same type of explanation, ie, a lower prevalence of health protecting behaviour among Roman Catholics. The high fertility rates among Roman Catholics in The Netherlands until the 1960s provide some indirect evidence for this. ${ }^{34}$

The importance of this "cultural" variable may be a feature distinguishing the geographical mortality pattern in The Netherlands from that in many other countries. On the other hand, the main finding from the analysis covering the complete period 1950-84 was that percentage Roman Catholic is gradually becoming less important as a determinant of geographical variation in mortality, and that part of its role seems to have been taken over by average income.

The increasing importance of the latter variable finds its parallel in comparable developments in the United States, where several studies did not find a negative association between average income and mortality at regional level around 1960, but later studies did. ${ }^{10}$ 35-37 $^{10}$ England and Wales, the association has been negative throughout the postwar period, but for cardiovascular diseases a positive association was found around 1950, which reversed in later years, just as in The Netherlands. ${ }^{38} 39$

The negative association between average income and regional mortality which has emerged in recent years in The Netherlands has also been demonstrated in studies on other levels of aggregation, eg, neighbourhoods in the city of Amsterdam, ${ }^{40}$ and individuals. ${ }^{41-43}$ The explanation of these mortality differences is likely to be rather complex because the causes of death for which these differences have been observed in the analysis reported here range from stomach cancer to chronic non-specific lung disease and from ischaemic heart disease to traffic accidents (table IV).

Whatever the specific explanations are, however, the evolution of the Dutch mortality pattern suggests that inequalities in health associated with economic position should become a priority of public health in The Netherlands, as it is already in some other countries.

The mortality data were supplied by the Netherlands Central Bureau of Statistics. The smoking data were made available by the Steinmetz Archive, Amsterdam, The Netherlands, with the generous permission of the Verenigde Nederlandse Uitgeversbedrijven BV. This study was supported by a grant from the Ministry of Welfare, Public Health and Culture, Rijswijk, The Netherlands.

1 Anonymous. World health statistics annuals. Geneva: World Health Organization, 1986

2 Muntendam P. Comparison of mortality rates of different provinces, with a reflection on child mortality (in Dutch). Tijdschr Soc Geneesk 1938; 16: 234-8. 
3 Hofstee EW. Short demographical history of The Netherlands from 1800 to the present (in Dutch). Haarlem: Fibula-van Dishoeck, 1981.

4 Jansen PC, Meere JMM de. The mortality pattern of Amsterdam 1774-1930 (in Dutch). Tijdschr Soc Geschied 1982; 8: 180-223.

5 Townsend P, Phillimore P, Beattie A. Health and deprivation; inequalities and the North. London: Croom Helm, 1988. 6 Carstairs V, Morris R. Deprivation: explaining differences BMF 1989; 299: 886-9.

7 Valkonen T, Notkola V. Influence of socio-economic and other factors on the geographical variation of mortality in Finland, Sweden and Norway. Yearbook of Population Research in Finland 1977; 15: 9-30.

8 Nizard A, Prioux F. La mortalité départementale en France. Population 1975; 30: 781-824.

9 Bozzo SR, Novak KM, Galdos F. Mortality, migration and Bozzo SR, Novak KM, Galdos F. Mortality, migration and
air pollution; a comparative study. Soc Sci Med 1979; 13D: air pollution.

10 Hadley J. More medical care, better health? Washington DC: Urban Institute Press, 1982.

11 Office of Population Censuses and Surveys. Occupational mortality 1979-80, 1982-83 Great Britain. London: HMSO, 1986.

12 Fox J, Jones D, Moser K, et al. Socio-demographic differentials in mortality 1971-81. Popul Trends 1985; 44: $10-16$

13 Valkonen T. Psychosocial stress and socio-demographic differentials in mortality from ischaemic heart disease in Finland. Acta Med Scand (Suppl) 1982; 66: 152-64.

14 Vågerö $D$, Lundberg $O$. Health inequalities in Britain and Sweden. Lancet 1989; ii: 35-36.

15 Kristoferson LB. Mortality by occupation; social differences in the 1970s. Oslo: Central Bureau of Statistics, 1986.

16 Lynge E. Occupational mortality in Denmark 1970-1975. Scand Popul Stud 1979; 5: 120-30.

17 Desplanques G. La mortalité des adultes; résultat de 2 études longitudinales (période 1955-1980). Paris: INSEE, 1984

18 Feldman JJ, Makuc DM, Kleinman JC, et al. National trends in educational differentials in mortality. Am $\mathcal{F}$ Epidemiol 1989; 129: 919-33.

19 Pearce N, Davis PB, Smith AH, Foster FH. Social class, ethnic group, and male mortality in New Zealand, 1974 1978. F Epidemiol Community Health 1985; 39: 9-14.

20 Joossens JV, Vuylsteek K, Brems-Heyns E, et al. The pattern of food and mortality in Belgium. Lancet 1977; i: 1069-72.

21 Lagasse R, Kittel F, Dramaix $M$, et al. Ischemic heart disease and regional variations of socio-cultural disease and regional variations of socio-cultural

22 Houte-Minet M van, Wunsch G. La mortalité masculine aux âges adultes II. Causes et déterminants régionaux. Working ages adultes II. Causes et déterminants régionaux. Working Paper No 1978 .

23 Mackenbach JP, Kunst AE, Looman CWN, et al. Regional differences in mortality from conditions amenable to medical intervention in The Netherlands: a comparison of four time periods. 7 Epidemiol Community Health 1988; 42: 325-32.

24 Levin JS, Schiller PL. Is there a religious factor in health? $\mathcal{F}$ Religion Health 1987; 26: 9-34.

25 Lyon JL, Wetzler HP, Gardner JW, et al. Cardiovascular mortality in Mormons and non-Mormons in Utah, 196971. Am $\mathcal{F}$ Epidemiol 1978; 108: 357-66.

26 Hamman RF, Barancik JI, Lilienfeld AM. Patterns of mortality in the old order Amish. Am $\mathcal{F}$ Epidemiol 1981; 114 845-61.

27 Phillips RL, Garfinkel L, Kuzma JW, et al. Cancer mortality among California Seventh Day Adventists for selected cancer sites. F Natl Cancer Inst 1980; 65: 1097-107.

28 Seidman $H$. Lung cancer among Jewish, Catholic and Protestant males in New York City. Cancer 1966; 19: 185-90.

29 Wardwell WI, Bahnson CB, Caron HS. Social and psychological factors in coronary heart disease. 7 Health psychological factors in cor

30 Weber M. The Protestant ethic (in German). Gütersloh: Gütersloher Verslagshaus Mohn, 1981.

31 Van Reek J. Smoking behaviour in The Netherlands (in Dutch). Tijdschr Alc Drugs 1983; 9(3): 99-103.

32 Van Reek J. Relation between smoking and religion (in Dutch). Medisch Contact 1984; 39: 1673-1674.

33 Stichting Nationaal Onderzoek Persmedia: Nationaa Onderzoek Persmedia 1972. Onderzoeksbestand PO351. Amsterdam: Steinmetzarchief.

34 Hemert MMJ van. Religious denominations (in Dutch) Monografieën volkstelling 1971, No 13. Voorburg: Centraal Bureau voor de Statistiek, 1979.

35 Kitagawa EM, Hauser PM. Differential mortality in the United States; a study in socio-economic epidemiology. United States; a study in socio-economic epidemiology.

36 Auster R, Leveson I, Sarachek D. The production of health an exploratory study. $¥$ Human Resources $1969 ; 4: 411-36$.

37 Lerner M, Stutz RN. Have we narrowed the gaps between the poor and nonpoor? Part II: mortality. Med Care 1977, 15: $620-35$

38 Gardner MJ. Using the environment to explain and predict mortality. $\mathcal{F} R$ Stat Soc $A$ 1973; 136: 421-40.

39 Pocock SJ, Shaper AG, Cook DG, et al. British Regiona Heart Study: geographic variations in cardiovascular mortality, and the role of water quality. BMF $1980 ; 280$ 1243-9.

40 Bos $T$ van de, Lau-Yzerman A, Habbema JDF, et al. Ill-health in a big city (in Dutch). Medisch Contact 1980; 35 : $335-40$

41 Mares NEHM, Aben DJM, Schouten EG et al. Income and mortality; results of a 25 year follow-up study of Amsterdam civil servants (in Dutch). Ned Tijdschr Geneeskd 1988; 132: 1109-12.

42 Otten F, Mendes de Leon CF, Appels A. The association between socio-economic status, health beliefs, risk factors, cardiac mortality and risk of dying (in Dutch). Maastricht: Rijksuniversiteit Limburg, 1989.

43 Doornbos G, Kromhout D. Educational level and mortality in a 32 year follow-up study of 18-year-old men in the Netherlands. Int $\mathcal{F}$ Epidemiol 1990; 19: 374-9. 